Textures and Microstructures, 1991, Vols 14-18, pp. 397-402 Reprints available from the publisher

Photocopying permitted by license only
(C) 1991 Gordon and Breach Science Publishers SA Printed in the United Kingdom

\title{
QUARTZ FABRIC AND MICROSTRUCTURAL ANAIYSIS OF MYLONITES FROM THE ELBE ZONE
}

\author{
K. Feldmann \\ Central Institute for Nuclear Research Rossendorf, Academy of Sciences of \\ GDR, P.0.Box 19, Dresden, 8051, GDR \\ E.Bankwitz, P.Bankwitz \\ Central Institute of the Physics of the Earth, Academy of Sciences of GDR, \\ Potsdam, 1500, GDR \\ W.KLeinsteuber, W.Voitus, K.Walther \\ Laboratory of Neutron Physics, Joint Institute for Nuclear Research Dubna, \\ Head Post office Box 79, Moscow, USSR
}

\section{INTRODUCTION}

Preferred orientation of minerals in rock units are related to the physical conditions in their formation history. Here, neutron time-of-flight (TOF) diffraction has been applied to investigate the quartz partial texture of quartzitic rocks from two selected places of the Central Saxonian shear zone (part of the

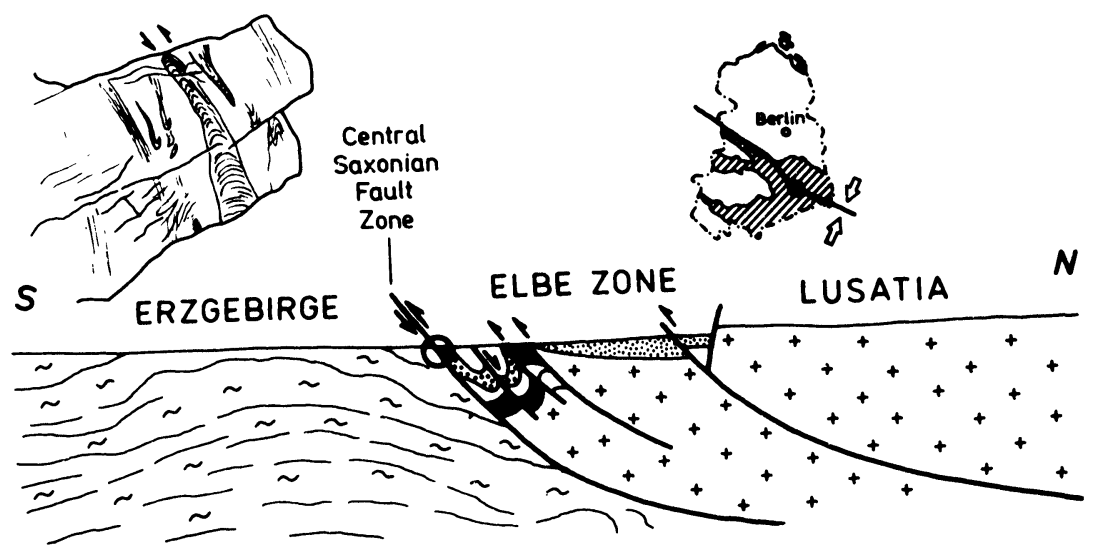

Figure 1 Section through the Elbe zone south of Dresden. The granodioritic Lusatian crust (right) is overthrusted on the Erzgebirge gneisses (left), shortening and folding the Paleozoic units of the Elbe synclinorium. 
Elbe zone) southeast of Dresden. The Elbe zone is one of the most important lineaments crossing Central Europe. This complex shear system represents the tectonic border between Proterozoic and Paleozoic units with a multistadial development. The shear zone is the border between the two crustal blocks of the Erzgebirge and Lusatia, which was overthrusting to the southwest (Fig.1). The spectrum of conditions during the structural evolution includes processes from earlier high temperature deformations up to younger small scale fault folding at decreased temperatures recognizable by a very strong lineation.

The texture data were discussed in the context with strain analyses and with computer simulations of possible deformation modes in quartz as well. The results found for the two specimens differ with respect to their texture sharpness as well as some of their characteristic texture components. They can be understood taking into account the different deformation conditions in the shear bonds itself and in the wider range of the shear system.

\section{EXPERIMENTS AND DATA HANDLING}

One sample (No.1501) is a blastomylonite of primary granitic composition, quartz content $30 \%$. Three deformation planes are to observe, partially the primary cleavage is eliminated by fault tectonics. The second specimen (1506) is also a blastomylonite (quartzite, quartz content $80 \%$ ). In this example the two main cleavage planes are well preserved. The younger cleavage has developed to on gliding system as in the case of 1501 .

The neutronographic texture studies have been performed by TOF diffraction at the NSWR TOF texture diffractometer /1/ of the IBR-2 pulsed reactor of the JINR Dubna 12/. The application of the TOF technique for texture analys is is described in $13,4,5 \%$. Three counters were used at the same time. The Bragg angles were selected from the four values $\vartheta=40^{\circ}, 50^{\circ}, 60^{\circ}$ and $70^{\circ}$ respectively to scan complete pole figures with constant tilt angle steps (10 deg.). The azimuth angle steps have been kept constant for fixed tilt angle. They varied from $10 \mathrm{deg}$. at the equator up to $36 \mathrm{deg}$. at the pole and its neighbourhood.

The samples were prepared as slabs of $1 \mathrm{~cm}$ thickness. The beam cross-section is $5 \mathrm{~cm}$ in diameter. In this way, the large irradiated volume $(>20 \mathrm{~cm})$ ensures a good grain statistics.

In the TOF method the complete Bragg pattern is recorded simultaneously at constant scattering geometry. Therefore, all pole figures under consideration are determined by only one scan. The pole density values are extracted from Bragg peaks by line profile analysis. From the complex diffraction spectrum superpositioned by patterns from all mineral contained in the sample only the quartz reflections could be resolved for further data handling. Furthermore, those quartz reflections had to be picked up where the influence of other phases is less than about $40 \%$. For the understanding of weak textures of all components the arising errors are supposed to be small. Taking into account all uncertainties of raw data, caused by the superposition of diffraction spectra of the coexisting mineral components, the experimental pole figures were checked and refined with respect to their internal and external compatibilities.

Mathematical texture analysis has been performed using the series expansion method $16 /$ up to $l=14$ for even $l$ only. Comparing experimental and recalculated pole figures as well as the $\mathrm{C}_{2}{ }^{\circ}$-coefficients for each pole figure uncertainties dependent on the tilt angle being caused by the use of several detectors and difficulties in background determination could be corrected. The coincident pole figures of the $(h k i l) /(k h i l)$ type are taken into account with respect to the method outlined in $17 /$.

Strain measurements have been performed analyzing the shape and the main axes of more than 100 grains in the $X Y, Y Z$ and the $X Z$ plane of the strain coordinate system respectively.

\section{RESULTS AND INTERPRETATION}

From TOF spectra 8 pole figures of the granitic blastomylonite and 10 pole figures of the quartzitic blastomylonite have been selected for the ODF reproduction. Their accuracies are given by the RP-values in Tab.1. The recalculated basal and prism pole figures are shown in Fig. 2 for the specimen 1501 and in Fig. 3 for the sample 1506 respectively. The sample coordinate system and the assumed strain 

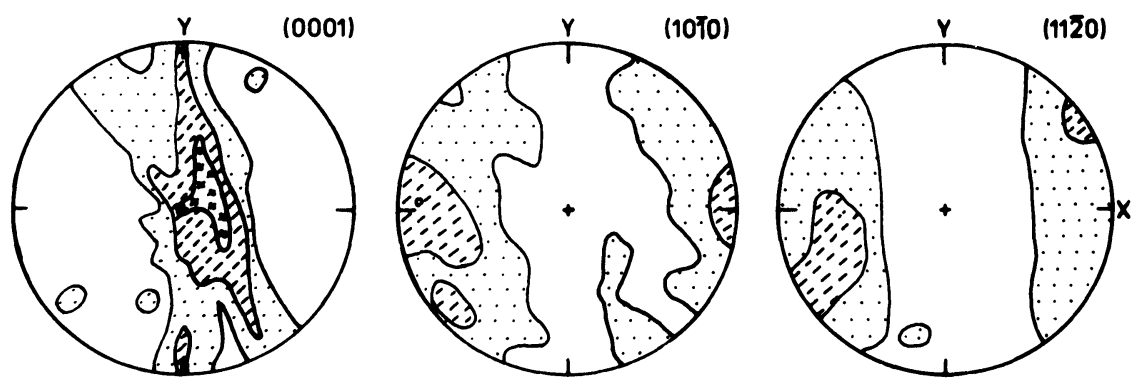

Figure 2 Recalculated basal and prism pole figures of the granitic blastomylonite. The contour line steps are 0.25 times m.r.d. starting at 1.0 times m.r.d.
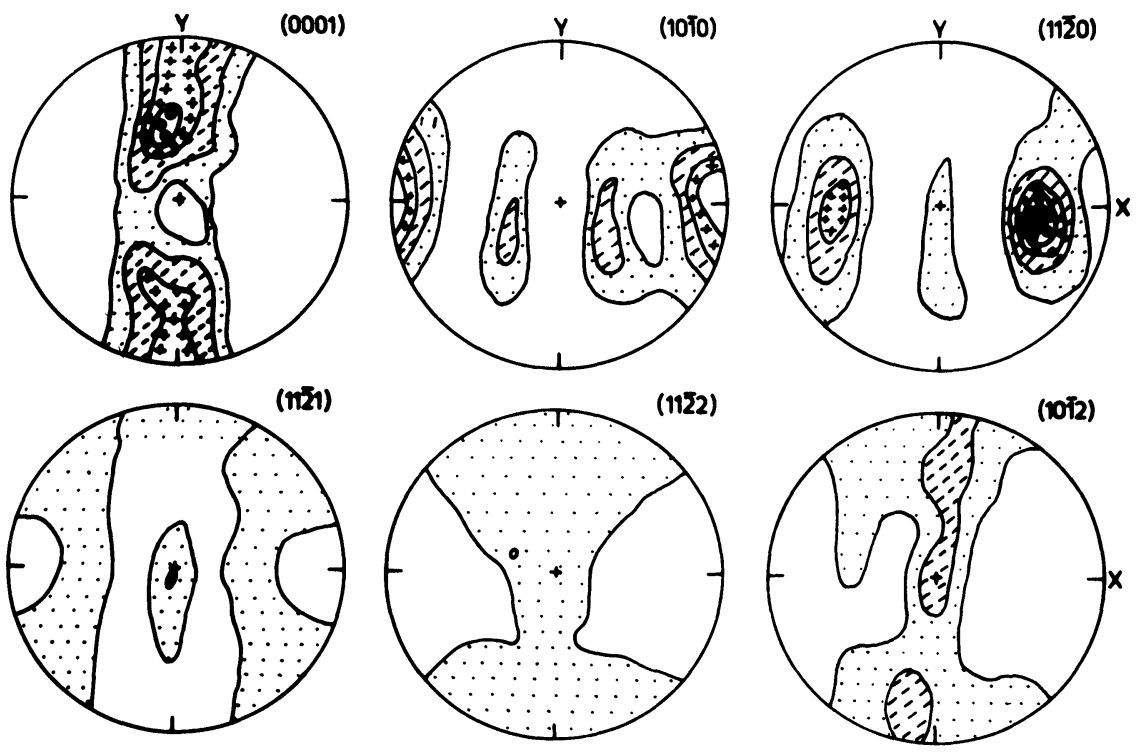

Figure 3 Recalculated pole figures of the quartzitc blastomylonite (1506). The contour line steps are 0.5 times m.r.d. starting at 1.0 times m.r.d.

coordinate system are parallel. The dominating characteristics for both samples are $y z$ girdles having variable intensities. For the rock 1501 all the girdle is somewhat inclined with respect to the yz direction (about $15 \mathrm{deg}$.). The maximum intensity is in the centre of the pole figure. At $y$ the yz girdle splits up similarly to crossed girdles with an opening angle of $30 \mathrm{deg}$. In the quartzite pole figure the girdle maximum is tilted against the pole for $45 \mathrm{deg}$. figure normale. A weaker maximum can be seen in the symmetric position on the girdle. Around $z$ the yz girdle seems to be superposed by crossed girdles with an opening angle of 50 deg. On the other hand the girdle may be interpreted to be weakened at $z$. Corre- 
Table 1. RP-values for the pole figures of the two specimens. only one Miller index is given for coincident pole figures. For all Bragg reflections contributing to pole figures see $/ 8$.

\begin{tabular}{lllllllllll}
\hline & $11 \overline{2} 0$ & $11 \overline{2} 1$ & $11 \overline{2} 2$ & $10 \overline{1} 1$ & $10 \overline{1} 2$ & $12 \overline{3} 0$ & $12 \overline{3} 1$ & $12 \overline{3} 2$ & $20 \overline{2} 1$ & $20 \overline{2} 2$ \\
\hline 1501 & 4.8 & 4.3 & - & - & 4.6 & 5.1 & 4.4 & 5.4 & 3.8 & 6.4 \\
1506 & 5.2 & 6.9 & 8.2 & 4.6 & 6.1 & 11.4 & 8.9 & 9.2 & 7.1 & 13.0 \\
\hline
\end{tabular}

sponding to the $y z$ girdles of the basal pole figures the prism-I pole figures of 1501 and 1506 show pronounced maxima in the $x$ direction. The 60 degree girdles around $x$ are indicated for 1506 but hardly visible for 1501. In the prism-II pole figures the 30 degree girdles around $x$ are discernible. The expected $y z$ girdle can be seen only for quartzite. Generally, the texture sharpness is significantly less for granitic blastomylonite than for quartzite. It is remarkable that the quartz c-axes of both specimens tend to orient perpendicularly to the strain extension axis as found at the study of orthogneisses $/ 8 /$ also.

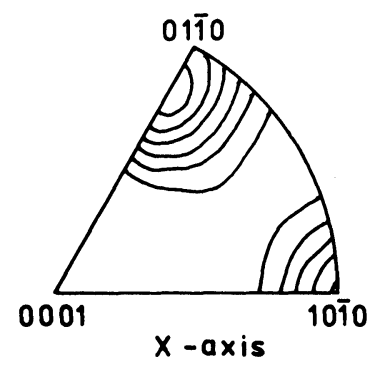

Figure 4 Inverse $x$-axis pole figure of 1506 .
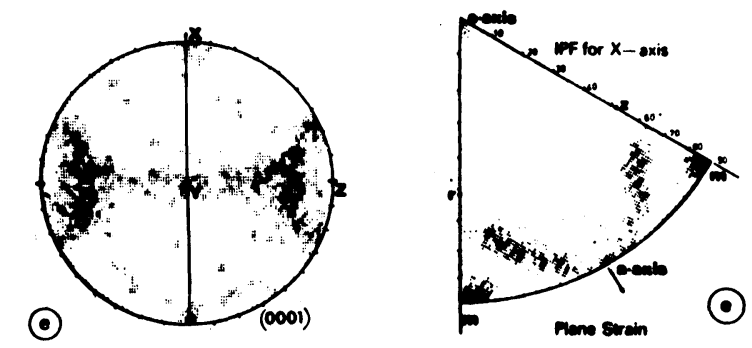

Figure 5 Theoretical pole figure and inverse pole figure according to Lister et al. $19 /$. 
Comparing the basal pole figure and the inverse pole figures (Fig.4) of 1506 with model calculations from $19 /$ shown in Fig. 5 the patterns are related to plane strain deformation, where \{basal\}<a> glide is easiest to operate, and the $r$ and $z$ rhomb systems have equal but higher critical stresses. The two girdle maxima may refer to simple shear components in the deformation mode. The results of the twodimensional strain analysis showing highly anisotropic grain shape orientation distribution (fluctuation 90 to 20 degrees) are presented in Fig. 6. The corresponding 3-dimensional value in the Flinn diagram is situated in the plain strain field but with a tendency to weak constriction.
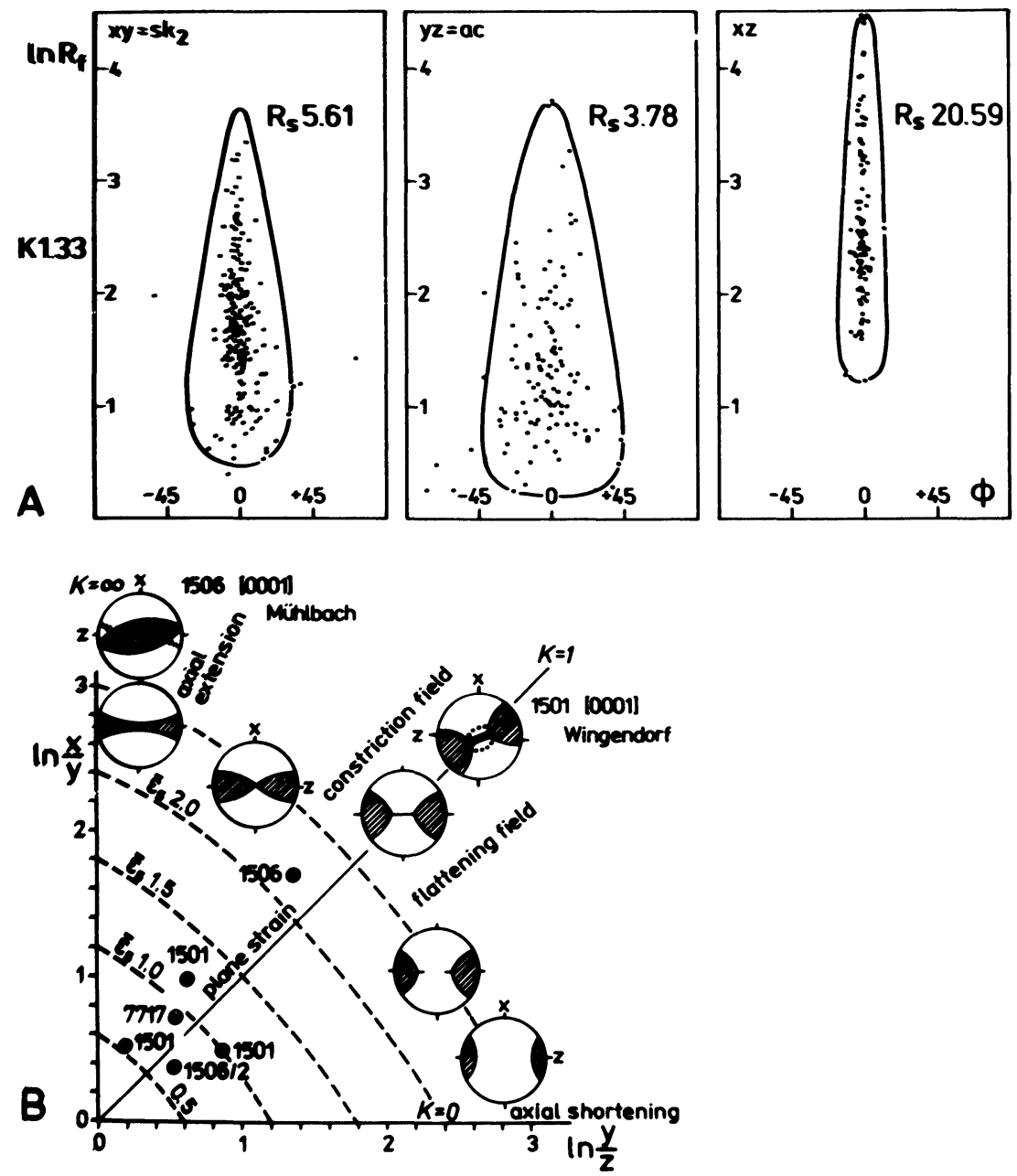

Figure 6 Strain analysis from two localities at the Central Saxonian fault zone. Plot of two-dimensional (A) for (1506 only) and three-dimensional (B) values calculated from thin section measurements. Comparision between neutron basal pole figures and relation of quartz axes fabrics and strain symmetry according to $/ 9 /$. 
The 1501 specimen has undergone a more complex deformation. The multiple tectonic processes in the main overthrust plane have destroyed the original texture in sample 1501 in a high degree. The grain size reduction is so strong that strain measurements on the base of individual grains do not represent the distortion. The type of deformation proved by the Flinn plot is clearly related to plane strain.

\section{CONCLUSION}

The quartzitic rock (1506) was deformed under low temperature but high pressure conditions. The type of the quartz girdle indicates a laminar gljding of the basal plane by shearing along two sets of gliding with an angle of $45^{\circ}$ to the main fault plane. These two gliding planes are symmetrically oriented to the main shortening axis and parallel to the extension direction. The pattern of the yzgirdle points to simple shear deformation under non-coaxial conditions. Comparing the texture characteristics with computer simulations and taking into account the strain values in the $\mathrm{Flinn}$ plot plane strain with a tendency to axial extension has to be assumed as the main deformation.

\section{REFERENCES}

1. B.N.Ananiev et al., JINR Communication P14-84-827, Dubna 1984, in Russian. 2. V.D.Ananiev et al., Proc. Int. Conf. on Neutron Scattering in the Nineties (IAEA, Vienna, 1985) p.63.

3. K.Feldmann, Proc. Workshop on Experimental Techniques of Texture Analysis, (Ed. H.J.Bunge, Oberursel, DGM Informationsgesel(schaft 1986), p.253.

4. K.Feldmann, Textures and Microstructures, 10, 309 (1989).

5. K.Feldmann et al., this volume.

6. H.J.Bunge, Texture Analysis in Material Science, Mathematical Methods, (Butterworth, London, 1982).

7. H.J.Bunge and H.R. Wenk, Tectonophysics, 40, 257 (1977).

8. V.Damm et al., Textures and Microstructures, 12, 15 (1990).

9. G.S.Lister et al., Tectonophysics, 45, 107 (1978). 